\title{
CHEMICAL LASERS FROM THE PHOTODISSOCIATION OF NITROSYL HALIDES
}

\author{
J. I. DEL BARRIO BARRERO and F. M. G.-TABLAS \\ Departmento de Química, Universidad Autónoma de Madrid 28049, Madrid, Spain
}

(Received 1 September, 1991; in final form 15 October, 1991)

\begin{abstract}
New NO laser emission from the photodissociation of BrNO has been observed between vib-rotational levels of the ground state of $\mathrm{NO}$, using $\mathrm{He}$ and $\mathrm{Br}_{2}$ as buffer gases. Also, from the $\mathrm{C} 1 \mathrm{NO}$ photodissociation several new NO vibro-rotational lines have been observed.

The presence of a buffer gas was necessary to observe laser emission from $\mathrm{BrNO}$ and $\mathrm{C} 1 \mathrm{NO}$.

The temporal behavior of the NO laser emission from the photodissociation of both nitrosyl halides has been studied.
\end{abstract}

KEY WORDS: Chemical lasers, photodissociation, nitrosyl halides.

\section{INTRODUCTION}

The photodissociation of NOX, specially $\mathrm{NOCl}$ have been studied extensively during the last decades. Goodeve and $\mathrm{Katz}^{1}$ were the first to analyze the spectrum of $\mathrm{NOCl}$ in the visible and ultraviolet regions.

Kistiakowsky ${ }^{2}$ studying the photodissociation of NOCl between 365 and $635 \mathrm{~nm}$ proposed two mechanisms to account for a quantum yield of nearly 2 .

The first mechanism:

$$
\begin{aligned}
& \mathrm{NOCl}+\mathrm{hv} \rightarrow \mathrm{NO}+\mathrm{Cl} \\
& \mathrm{Cl}+\mathrm{NOCl} \rightarrow \mathrm{NO}+\mathrm{Cl}_{2}
\end{aligned}
$$

the second mechanism:

$$
\begin{aligned}
\mathrm{NOCl}+\mathrm{hv} & \rightarrow \mathrm{NOCl}^{*} \\
\mathrm{NOCl}^{*}+\mathrm{NOCl} & \rightarrow 2 \mathrm{NO}+\mathrm{Cl}_{2}
\end{aligned}
$$

Although Kistiakowsky favor the second, Basco and Norrish ${ }^{3}$, using the flashphotolysis technique, observed that the NO production during the photodissociation was independent of the pressure of inert gases added to the reaction, proving that the reaction followed the first mechanism and not the second.

Several authors ${ }^{4-9}$ have corroborated the above mechanism and recently Reisler et al. ${ }^{10}$ using vector correlations and ab initio calculations have studied in detail the photodissociation dynamics of $\mathrm{NOCl}$ from the $T_{1}\left(1^{3} A^{\prime \prime}\right)$ and the $S_{1}\left(1^{1} A^{\prime \prime}\right)$.

A chemical laser is the coherent radiation collected from the population inversion obtained by breaking or reordering the bonds of one or several molecules.

To reach this situation is necessary to place our system as far away as possible from equilibrium. The states of the fragments involved can be electronic, vibrational or rotational. 
The techniques used to break or reorder the bonds of the molecules require inelastic collisions with photons, pumping by flash or other lasers, or electrons in discharges. The pure chemical lasers use only the exothermicity of the chemical reaction to produce the necessary population inversion.

G. C. Pimental et al. ${ }^{11-13}$ were the first to observe laser action following flash photodissociation processes.

M. A. Pollack ${ }^{14}$ observed vibrational-rotational $(v=7,8$ and 9$)$ laser emission from the ground state of $\mathrm{NO}$, between 5.95 and 6.30 microns, after photodissociating NOCl.

Deutsch ${ }^{15}$ using an electrically pulsed discharge observed more lines, up to $v=11$, flowing a mixture of $\mathrm{NOCl}$ and $\mathrm{He}$. Giuliano and $\mathrm{Hess}^{16}$ obtained reversible laser emission from mixtures of $\mathrm{Cl}_{2}$ and $\mathrm{NOCl}$ but did not analyze the $V-R$ components.

We have observed several new $(V-R)$ laser lines after flash-dissociating $\mathrm{NOCl}$. Using $\mathrm{He}$ and $\mathrm{Br}_{2}$ as buffer gases we have obtained for the first time NO laser emission from NOBr photodissociation.

During the rest of the article we summarized our own results.

\section{EXPERIMENTAL}

A concentrical suprasil lamp, filled with 20 Torr of Xe, $37 \mathrm{~cm}$ long, produced flashes that reached maximum intensity in $2 \mu \mathrm{s}$, discharging a $2.5 \mu$ farad capacitor charged to $18 \mathrm{Kv}$. The cavity, $90 \mathrm{~cm}$ long, was hemiconfocal and formed by a gold coated flat and a 2 meter of curvature spherical mirror.

$\mathrm{NOCl}$ and $\mathrm{NOBr}$ were synthesized from $\mathrm{Cl}_{2}, \mathrm{Br}_{2}$ and $\mathrm{NO}$ and carefully purified from bulb to bulb distillations.

The lines were analyzed with a 1 meter Jarrell Ash monochromator provided with a grating blazed at 5 microns. Gold doped infrared detectors were used at $77 \mathrm{~K}$.

To avoid water atmospheric absorption the cavity was purged with dried nitrogen.

\section{RESULTS}

\section{Observed Lines and Assignments}

Tables 1 and 2 show the measured wavelengths and the assignments of the NO laser emission from the photodissociation of $\mathrm{NOCl}$ and $\mathrm{NOBr}$. As in most chemical lasers, due to their higher gain, the observed transitions have been assigned to the $\mathrm{P}$ branch.

The NO laser emission reaches vibrational levels 9 to 8 in NOCl, but only 7 to 6 in NOBr. This behavior does not seem to be correlated to the strength of the corresponding halogen-nitrogen bond. The intensities of the observed lines are more evenly distributed in the $\mathrm{NOBr}$ than in the $\mathrm{NOCl}$ laser. It is remarkable to observe that a large part of the laser energy in $\mathrm{NOCl}$ is concentrated in the $\Pi_{3 / 2}$ 7-6 line.

\section{Overlap with Atmospheric Water Absorption}

The normal symmetric bending mode of water overlaps, around six microns, with the NO laser emission. To avoid this absorption we have purged the optical cavity 
Table 1 Measured vacuum wavelengths and frequencies, calculated frequencies, and identifications of NO laser transitions from CINO photodissociation

\begin{tabular}{|c|c|c|c|c|c|}
\hline \multirow{3}{*}{$\begin{array}{l}\text { Measured } \\
\text { vacuum } \\
\text { wavelength } \\
(\mu m)\end{array}$} & \multicolumn{3}{|c|}{ Identification } & \multirow{3}{*}{$\begin{array}{l}\text { Frequency } \\
\left(\mathrm{cm}^{-1}\right)\end{array}$} & \multirow{3}{*}{$\begin{array}{l}\text { Calculated } \\
\text { frequency } \\
\left(\mathrm{cm}^{-1}\right)\end{array}$} \\
\hline & \multirow[t]{2}{*}{$\begin{array}{l}\text { Vibrational } \\
\text { band }\end{array}$} & \multicolumn{2}{|c|}{$\begin{array}{c}\text { Transition } \\
\mathrm{P}(\mathrm{J}-1 / 2) \text { substate }\end{array}$} & & \\
\hline & & ${ }^{2} \Pi_{1 / 2}$ & ${ }^{2} \Pi_{3 / 2}$ & & \\
\hline $\begin{array}{l}5.7762 \\
5.7882 \\
5.8010\end{array}$ & $5 \rightarrow 4$ & & $\begin{array}{l}P(9) \\
P(10) \\
P(11)\end{array}$ & $\begin{array}{l}1731.23 \\
1727.65 \\
1723.84\end{array}$ & $\begin{array}{l}1731.15 \\
1727.53 \\
1723.86\end{array}$ \\
\hline $\begin{array}{l}5.8466 \\
5.8554 \\
5.8594 \\
5.8714 \\
5.8794 \\
5.9081\end{array}$ & $6 \rightarrow 5$ & $\begin{array}{l}\mathrm{P}(8) \\
\mathrm{P}(10)\end{array}$ & $\begin{array}{l}\mathrm{P}(7) \\
\mathrm{P}(8) \\
\mathrm{P}(9) \\
\mathrm{P}(12)\end{array}$ & $\begin{array}{l}1710.40 \\
1707.83 \\
1706.67 \\
1703.18 \\
1700.87 \\
1692.58\end{array}$ & $\begin{array}{l}1710.58 \\
1708.17 \\
1707.05 \\
1703.50 \\
1701.27 \\
1692.62\end{array}$ \\
\hline $\begin{array}{l}5.9545 \\
5.9629 \\
5.9673 \\
5.9753 \\
5.9793 \\
5.9881 \\
5.9929 \\
6.0009 \\
6.0057 \\
6.0264 \\
6.0328\end{array}$ & $7 \rightarrow 6$ & $\begin{array}{l}P(9) \\
P(10) \\
P(11) \\
P(12) \\
P(14)\end{array}$ & $\begin{array}{l}P(8) \\
P(9) \\
P(10) \\
P(11) \\
P(12) \\
P(14)\end{array}$ & $\begin{array}{l}1679.40 \\
1677.04 \\
1675.80 \\
1673.56 \\
1672.44 \\
1669.99 \\
1668.65 \\
1666.43 \\
1665.09 \\
1659.35 \\
1657.59\end{array}$ & $\begin{array}{l}1679.36 \\
1677.05 \\
1675.84 \\
1673.59 \\
1672.28 \\
1670.10 \\
1668.69 \\
1666.57 \\
1665.07 \\
1659.40 \\
1657.72\end{array}$ \\
\hline $\begin{array}{l}6.0416 \\
6.0544 \\
6.0624 \\
6.0800 \\
6.0880 \\
6.0928 \\
6.1008 \\
6.1208 \\
6.1420\end{array}$ & $8 \rightarrow 7$ & $\begin{array}{l}P(9) \\
P(11) \\
P(12) \\
P(15)\end{array}$ & $\begin{array}{l}P(7) \\
P(8) \\
P(10) \\
P(11) \\
P(13)\end{array}$ & $\begin{array}{l}1655.18 \\
1651.68 \\
1649.51 \\
1644.73 \\
1642.58 \\
1641.28 \\
1639.13 \\
1633.78 \\
1628.14\end{array}$ & $\begin{array}{l}1655.12 \\
1651.67 \\
1649.40 \\
1644.66 \\
1642.51 \\
1641.11 \\
1639.02 \\
1633.90 \\
1628.33\end{array}$ \\
\hline $\begin{array}{l}6.1536 \\
6.1663 \\
6.1707 \\
6.1791 \\
6.1839 \\
6.1923 \\
6.1975 \\
6.2047 \\
6.2103 \\
6.2183 \\
6.2247 \\
6.2327\end{array}$ & $9 \rightarrow$ & $\begin{array}{l}P(8) \\
P(9) \\
P(10) \\
P(11) \\
P(12) \\
P(13) \\
P(14)\end{array}$ & $\begin{array}{l}P(9) \\
P(10) \\
P(11) \\
P(12) \\
P(13)\end{array}$ & $\begin{array}{l}1625.08 \\
1621.71 \\
1620.55 \\
1618.35 \\
1617.09 \\
1614.90 \\
1613.55 \\
1611.68 \\
1610.23 \\
1608.16 \\
1606.50 \\
1604.44\end{array}$ & $\begin{array}{l}1625.11 \\
1621.75 \\
1620.52 \\
1618.35 \\
1617.04 \\
1614.93 \\
1613.52 \\
1611.47 \\
1609.97 \\
1607.97 \\
1606.38 \\
1604.44\end{array}$ \\
\hline
\end{tabular}


Table 2 NO laser emission from BrNO photodissociation

\begin{tabular}{|c|c|c|c|c|c|}
\hline $\begin{array}{l}\text { Measured } \\
\text { wavelength } \\
\text { (vacuum) } \\
(\mu \mathrm{m})\end{array}$ & $\begin{array}{l}\text { Vibrational } \\
\text { band }\end{array}$ & $\begin{array}{l}\text { Transition } \\
\mathrm{P}(\mathrm{J}-1 / 2) \\
\text { substate } \\
{ }^{2} \Pi_{1 / 2}\end{array}$ & ${ }^{2} \Pi_{3 / 2}$ & $\begin{array}{l}\text { Measured } \\
\text { frequency } \\
\left(\mathrm{cm}^{-1}\right)\end{array}$ & $\begin{array}{l}\text { Calculated } \\
\text { frequency } \\
\left(\mathrm{cm}^{-1}\right)\end{array}$ \\
\hline $\begin{array}{l}5.6515 \\
5.6603 \\
5.6631 \\
5.6715 \\
5.6819 \\
5.6979 \\
5.7015\end{array}$ & $4 \rightarrow 3$ & $\begin{array}{l}P(7) \\
P(8) \\
P(9) \\
P(11)\end{array}$ & $\begin{array}{l}P(6) \\
P(7) \\
P(10)\end{array}$ & $\begin{array}{l}1769.43 \\
1766.69 \\
1756.81 \\
1763.20 \\
1759.97 \\
1755.01 \\
1752.82\end{array}$ & $\begin{array}{l}1769.60 \\
1767.04 \\
1766.04 \\
1763.55 \\
1760.01 \\
1755.15 \\
1752.85\end{array}$ \\
\hline $\begin{array}{l}5.7411 \\
5.7530 \\
5.7762 \\
5.7850 \\
5.7890 \\
5.7970\end{array}$ & $5 \rightarrow 4$ & $\begin{array}{l}P(10) \\
P(11)\end{array}$ & $\begin{array}{l}P(6) \\
P(7) \\
P(9) \\
P(10)\end{array}$ & $\begin{array}{l}1741.84 \\
1738.21 \\
1731.23 \\
1728.60 \\
1727.41 \\
1725.03\end{array}$ & $\begin{array}{l}1741.83 \\
1738.31 \\
1731.15 \\
1728.83 \\
1727.53 \\
1725.26\end{array}$ \\
\hline $\begin{array}{l}5.8434 \\
5.8546 \\
5.8706 \\
5.9081\end{array}$ & $6 \rightarrow 5$ & $\begin{array}{l}P(7) \\
P(8)\end{array}$ & $\begin{array}{l}\mathbf{P}(9) \\
\mathbf{P}(12)\end{array}$ & $\begin{array}{l}1711.34 \\
1708.07 \\
1703.41 \\
1692.58\end{array}$ & $\begin{array}{l}1711.60 \\
1708.17 \\
1703.50 \\
1692.62\end{array}$ \\
\hline $\begin{array}{l}5.9545 \\
5.9753 \\
6.0009 \\
6.0057\end{array}$ & $7 \rightarrow 6$ & $\begin{array}{l}P(10) \\
P(12)\end{array}$ & $\begin{array}{l}P(8) \\
P(12)\end{array}$ & $\begin{array}{l}1679.40 \\
1673.56 \\
1666.43 \\
1665.09\end{array}$ & $\begin{array}{l}1679.36 \\
1673.59 \\
1666.57 \\
1665.07\end{array}$ \\
\hline
\end{tabular}

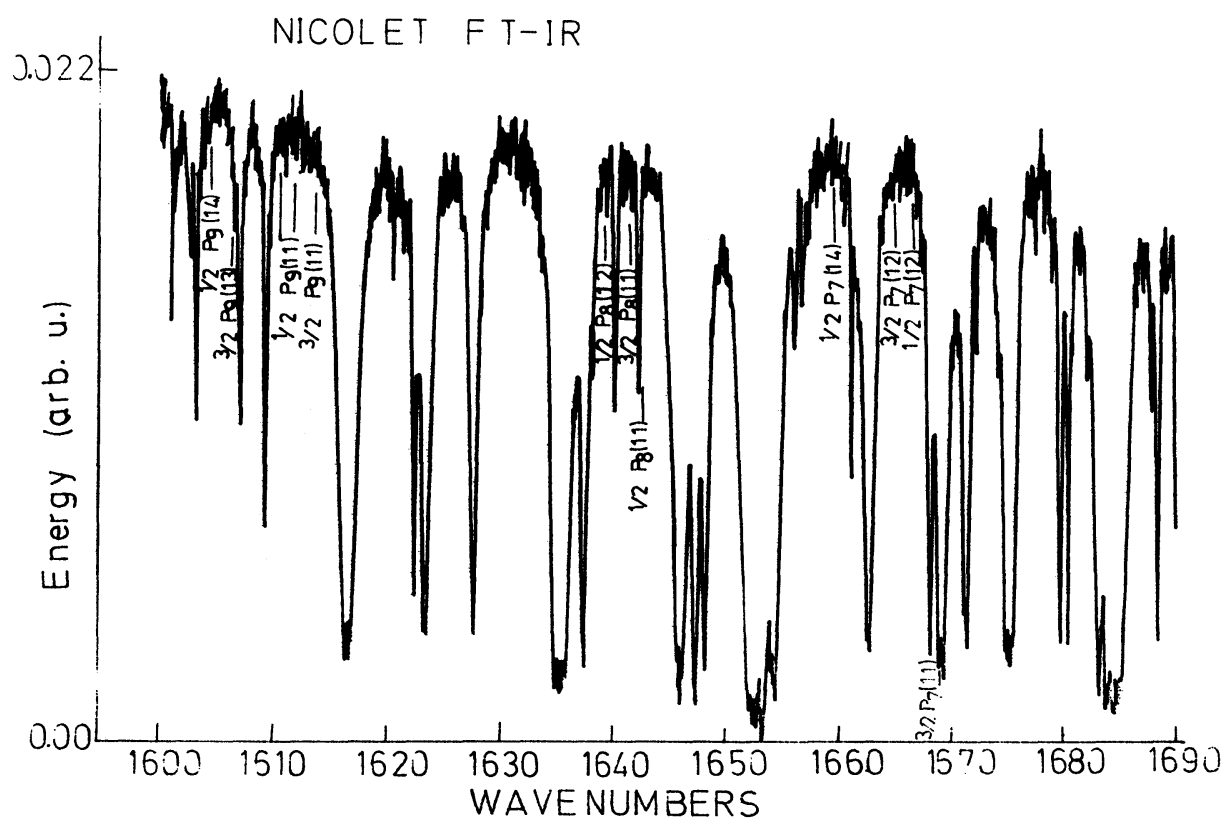

Figure 1 Atmospheric water band absorption with some NO lines superimposed. 
with dried nitrogen ${ }^{17,18}$. Several new lines were detected in the $\mathrm{NOCl}$ laser and many other lines increased substantially their intensities.

Figure 1 shows how the lines that increased most their intensities, when purging, sit on the maximum of the water band and those that decrease coincide with windows in the water spectrum. Figure 2 presents the effect of purging on total laser emission.

\section{Buffer effects on Laser Intensities}

The presence of a buffer gas was necessary to observe laser emission. Helium, chlorine and bromine were used as buffer gases. It seems that the lower vibrational bands only appear with He. When the halogens are used, reaction (1.b) becomes important and tends to populate the lower vibrational levels avoiding the population inversion in the final steps of the laser cascade.

As buffer pressure increases we have observed that the substate ${ }^{2} \Pi_{1 / 2}$ becomes more intense while the ${ }^{2} \Pi_{3 / 2}$ weakens ${ }^{17}$. This behavior was attributed to a funnelling of population from ${ }^{2} \Pi_{3 / 2}$ to ${ }^{2} \Pi_{1 / 2}$. The higher degeneracies of rotational levels, for similar energies, can explain this population transfer.

\section{Temporal Behavior}

The time evolution of the laser lines has been studied ${ }^{19}$. Figures 3 and $4(a)$, (b) show the temporal evolution of the rotational-vibrational transitions that correspond to the substates $X^{2} \Pi_{1 / 2}$ and $X^{2} \Pi_{3 / 2}$ respectively. The start of the laser pulse defines
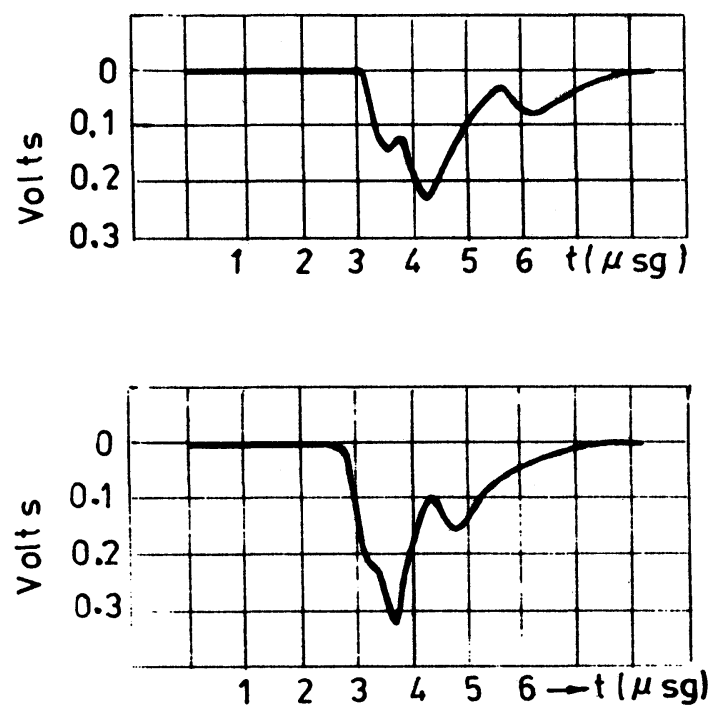

Figure 2 Total laser emission for 22.5 Torr of $\mathrm{BrNO}+\mathrm{He} 1: 70$ with (upper trace) and without (lower) purging. 


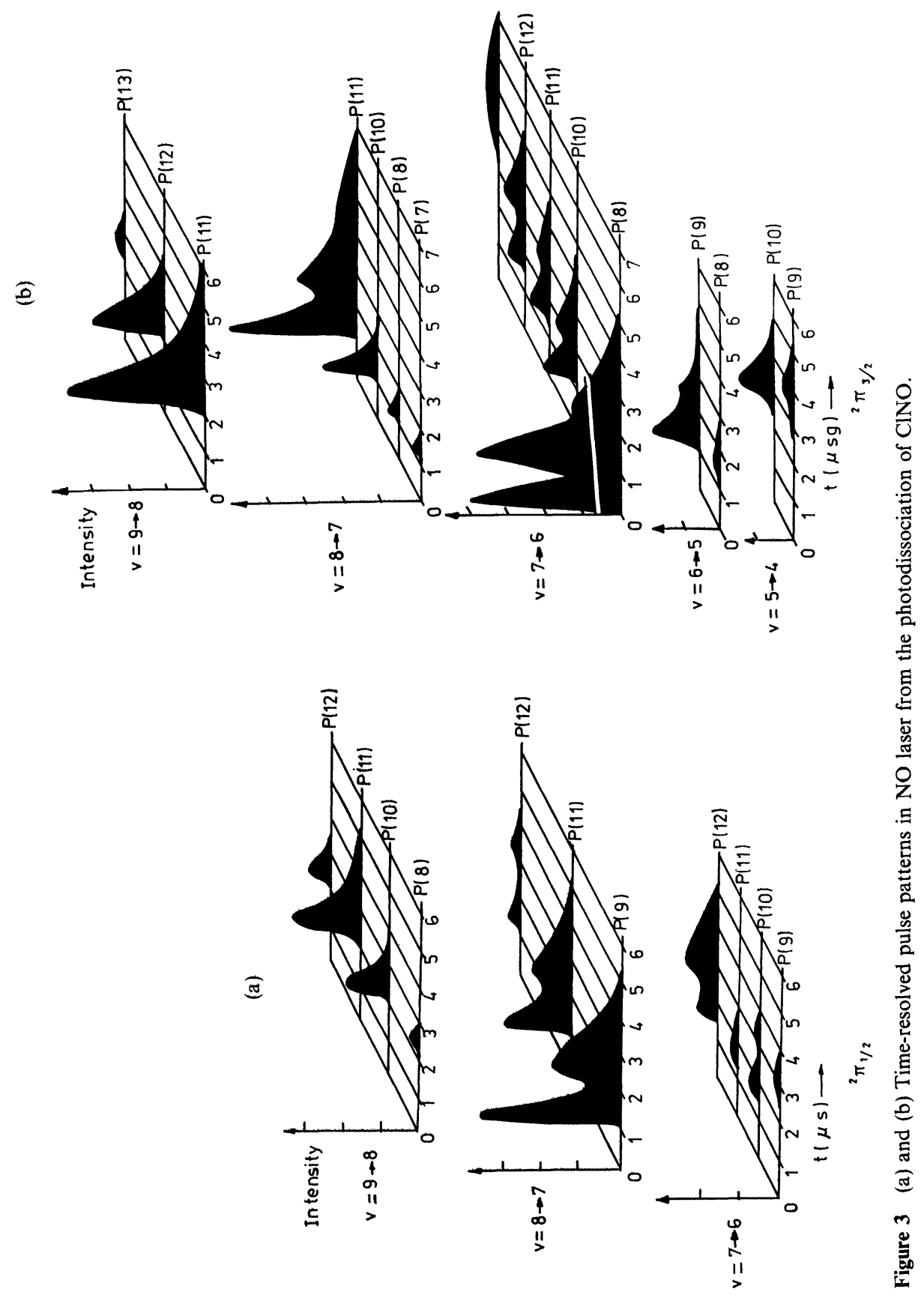


(a)
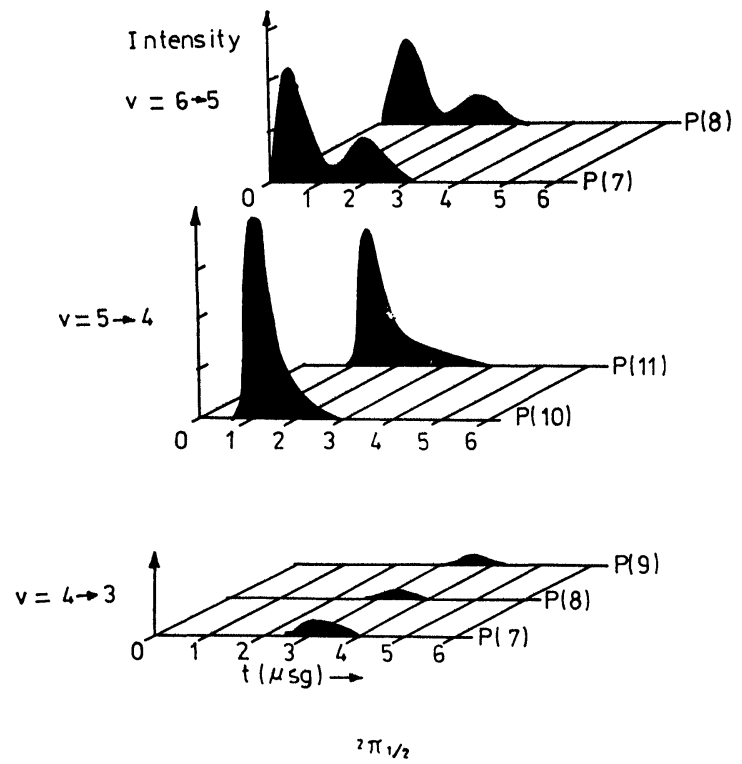

(b)
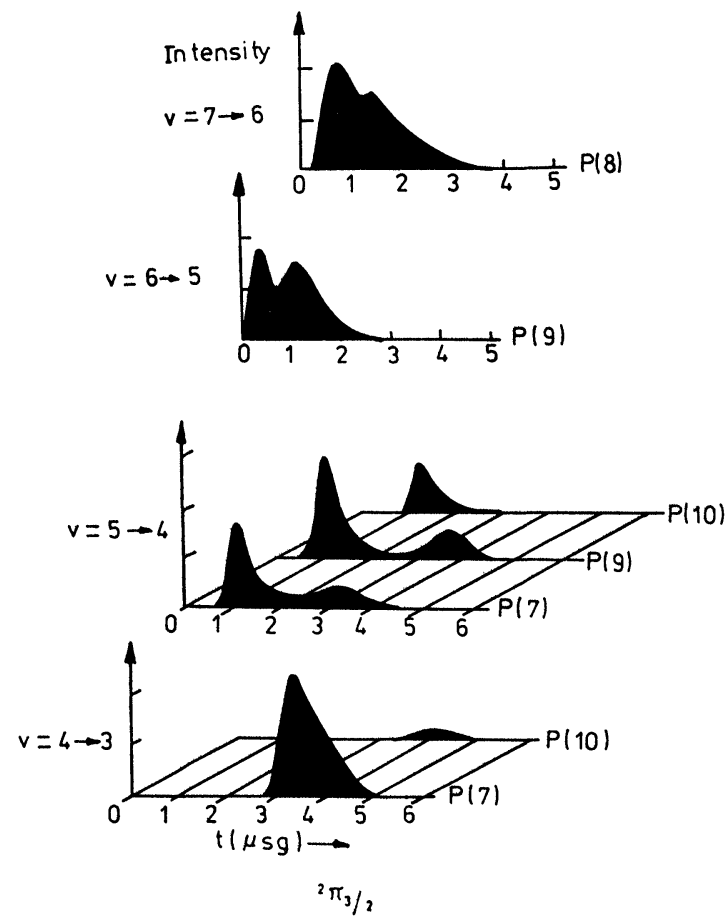

Figure 4 (a) and (b) Time-resolved pulse patterns in NO laser from the photodissociation of BrNO. 
$t=0 ;$ it takes place $\simeq 2.2 \mu$ s after the beginning of the flash for $\mathrm{NOCl}$ and $\simeq 3.3 \mu \mathrm{s}$ for NOBr. This seems to indicate a lower gain for this laser.

In general, the $J$ shifting typical of rotational equilibrated chemical lasers is not observed. All transitions starting from the same level laser simultaneously, except the $v=7 \rightarrow 6$ band. The relative intensities of the observed lines indicate that within a vibrational level the population among the rotational levels is rapidly distributed in both lasers.

The NO formed from the dissociation of $\mathrm{NOCl}$ appears mainly in $v=7$, being the $P(8)$ transition of the substate $\Pi_{3 / 2}$ the one that shows the maximum gain in both lasers.

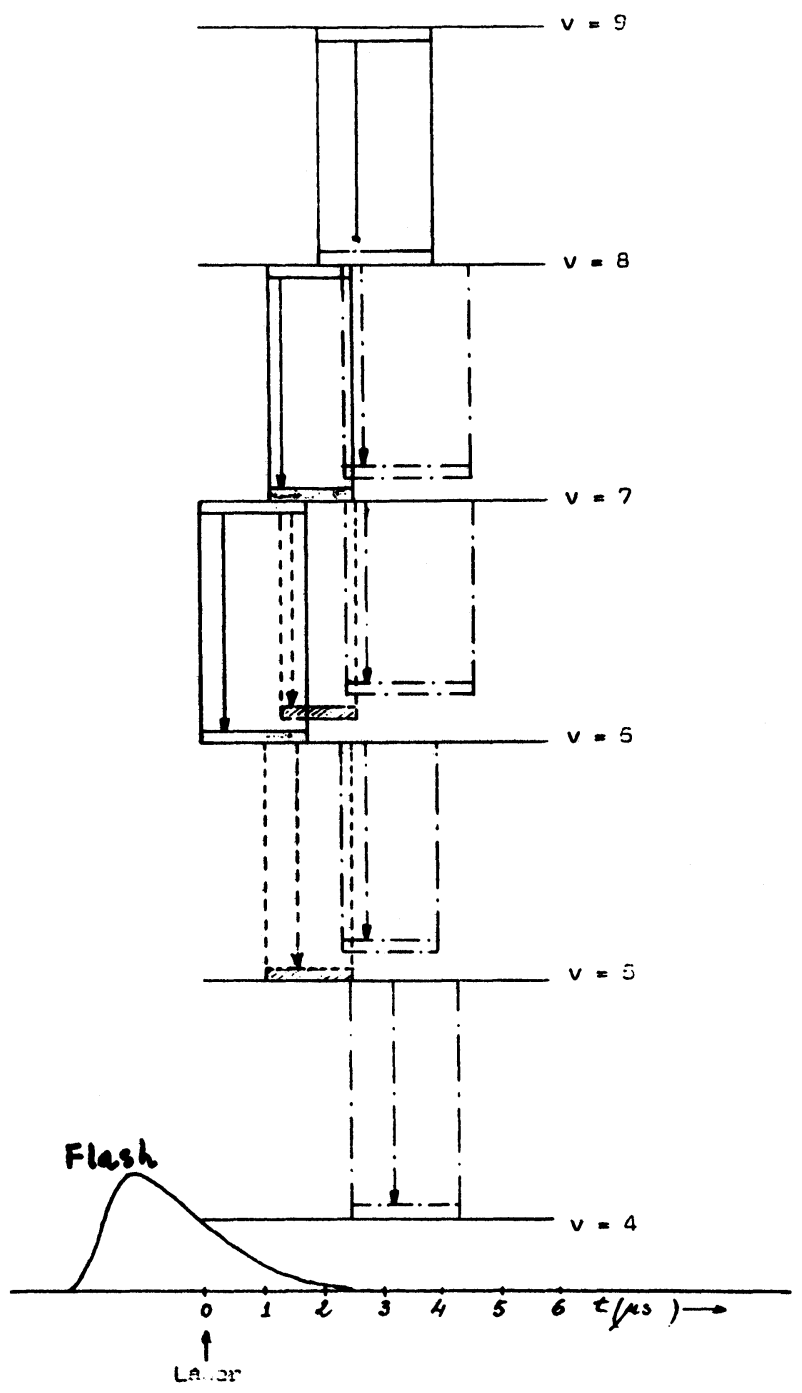

Figure 5 Time evolution of the laser cascade from CINO. 


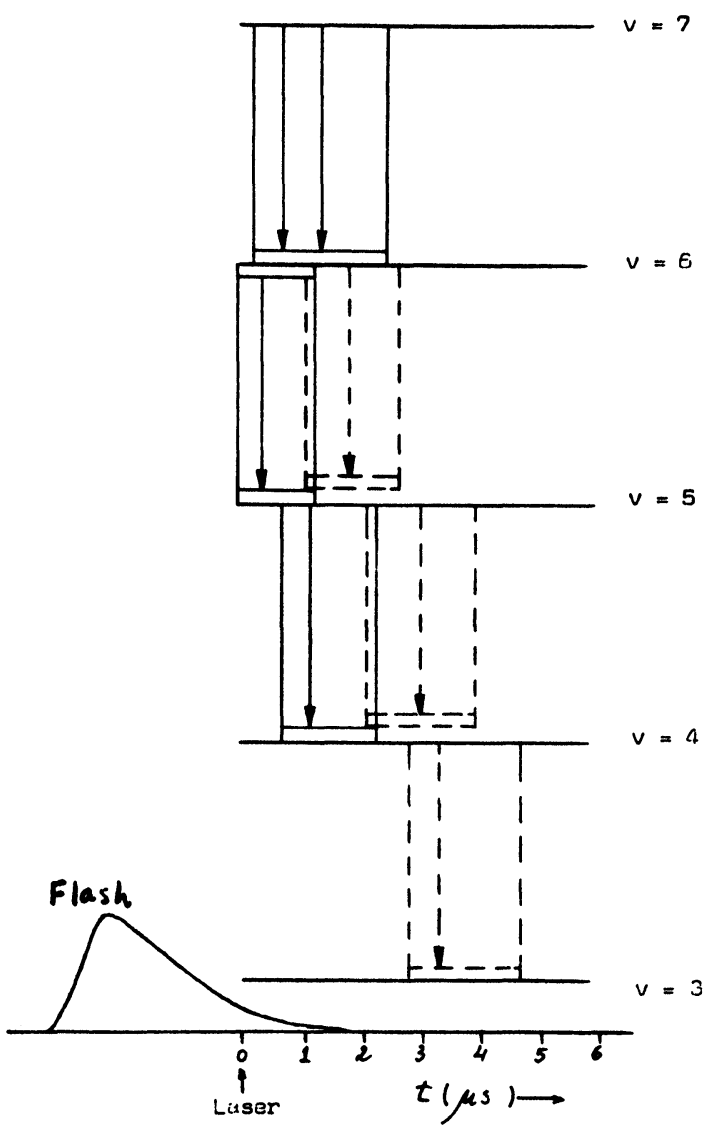

Figure 6 Time evolution of the laser cascade from BrNO.

Within each vibrational band all the rotational transitions take place simultaneously. This behavior seems to indicate lack of rotational equilibration. However, the relative intensities and the pressures used in our experiments would seem to indicate that rotational equilibration has been achieved before lasing starts.

Figures 5 and 6 show the time evolution of the laser cascade from CINO and $\mathrm{BrNO}$, respectively. In both cases, the first band to appear corresponds to an intermediate vibrational level, originating two sequences. The lowest vibrational band is the last to appear in both lasers.

\section{Acknowledgements}

We thank the CAYCIT for its support.

\section{References}

1. C. F. Goodeve and S. Katz, Proc. R. Soc. London Ser. A172, 432 (1939).

2. G. B. Kistiaskowsky, J. Am. Chem. Soc. 52, 102 (1930). 
3. N. Basco and R. G. W. Norrish, Proc. Roy. Soc. A268, 291 (1962).

4. G. E. Busch and K. R. Wilson, J. Chem. Phys. 56, 3655 (1972).

5. A. J. Grimley and P. L. Houston, J. Chem. Phys. 72, 1471 (1980).

6. L. Werner, B. Wunderer and H. Walther, Chem. Phys. 60, 109 (1981).

7. K. H. Welge, J. Chem. Phys. 45, 1113 (1966).

8. F. Lahmani, C. Lardeux and D. Solgadi, J. Chem. Phys. 77, 275 (1982).

9. M. D. Moser, E. Weitz and G. C. Schatz, J. Chem. Phys. 78, 757 (1983).

10. (a) Y. Y. Bai, A. Ogai, C. X. W. Qian, L. Iwata, G. A. Segal and H. Reisler, J. Chem. Phys. 90, 3903 (1989).

(b) C. X. W. Quian, A. Ogai, L. Iwata and H. Reisler, J. Chem. Phys. 92, 4296 (1990).

(c) A. Ogai, C. X. W. Quian and H. Reisler, J. Chem. Phys. 93, 1107 (1990).

11. J. V. V. Kasper and G. C. Pimentel, Appl. Phys. Letters 3, 231 (1964).

12. J. V. V. Kasper and G. C. Pimentel, Phys. Rev. Letters 14, 352 (1965).

13. M. J. Molina and G. C. Pimentel, J. Chem. Phys. 56, 3988 (1972).

14. M. A. Pollack, Appl. Phys. Letters 9, 94 (1966).

15. T. F. Deutsch, Appl. Phys. Letters 9, 295 (1966).

16. C. R. Giulano and L. D. Hess, J. Appl. Phys. 38, 4451 (1967).

17. J. I. del Barrio, J. R. Rebato and F. M. G.-Tablas, Chem. Phys. Letters 122, 59 (1985).

18. J. I. del Barrio, J. R. Rebato and F. M. G.-Tablas, Optics Comm. 55, 280 (1985). 